\title{
Cia. de Dança Palácio das Artes: movimentos de uma dança de resistência
}

\author{
TÂNIA MARA SILVA MEIRELES
}

Tânia Mara Silva Meireles é Artista Plástica, Bailarina, Coreógrafa e Maître de Balé, Mestre e Doutora em Artes pela escola de Belas Artes da UFMG, Docente do Bacharelado em Teatro e da Licenciatura em Dança do Departamento de Artes Cênicas (ARC-EBA/UFMG).

AFILIAÇÃO: Universidade Federal de Minas Gerais (UFMG) - Belo Horizonte, MG - Brasil. 


\section{- RESUMO}

Este artigo aborda a Cia. de Dança Palácio das Artes - CDPA, companhia de dança estatal localizada em Belo Horizonte, sob a perspectiva dos movimentos de transformação da dança teatral contemporânea pela qual a Companhia tem se recriado em seu processo profissional contínuo de mais de quatro décadas de existência, e resistência. Para tanto, analisando-se algumas experiências decorridas de seus procedimentos técnico-artísticos e reflexivos ao longo de sua trajetória artística. Como intermediação das transformações analisadas, propõe-se um paralelo entre a CDPA e o entendimento de experiência contido no ensaio O Narrador, de Walter Benjamin, para quem esta se torna conhecimento pelo acúmulo, prolongamento e desdobramento dessa experiência. Apresenta-se o entendimento de que, apesar de ser a Companhia Oficial de Dança do Estado de Minas Gerais, a Cia não se vê isenta de enfrentar desafios, mantendo-se em cena com dinâmicas que podem ser entendidas como movimentos de uma dança de resistência contínua e em interação com o contexto comumente presente na dança teatral contemporânea.

\section{PALAVRAS-CHAVE}

Cia. de Dança Palácio das Artes, experiência, movimentos, dança de resistência.

\section{ABSTRACT}

This article refers to the official dance company named Cia de Dança Palácio das Arte - CDPA located in the city of Belo Horizonte, under the perspective of the contemporary theatrical dance transformations movements for which the Cia has been recreated in its continuous professional process for more than four decades of existence, and resistance. In order to do so, an analysis is proposed observing some of the experiences contained in his technical-artistic and reflexive procedures throughout his artistic trajectory. As an intermediation of the analyzed transformations a parallel is drawn between the experience developed by the CDPA and the understanding of experience contained in Walter Benjamin's essay untitled "The Narrator". The author understands experience becomes knowledge by accumulation, extension and unfolding of this experience. This article proposes the understanding that, despite of being the Official Dance Company the CDPA does not see itself exempt from facing challenges, remaining in the scene with dynamics of a dance that may be understood as movements of continuous resistance and in interaction with the context commonly present in contemporary theatrical dance.

\section{KEYWORDS}

Cia. de Dança Palácio das Artes, experience, movements, resistance dance. 


\section{Introdução}

Aborda-se neste artigo a Cia. de Dança Palácio das Artes - CDPA, Companhia estatal localizada em Belo Horizonte, sob a perspectiva dos movimentos de transformação da dança teatral contemporânea pela qual a Companhia tem se recriado em seu processo profissional contínuo de mais de quatro décadas de existência, e resistência. Analisando-se, nesse sentido, algumas experiências decorridas de seus procedimentos técnico-artísticos e reflexivos ao longo de sua trajetória artística. Como intermediação das transformações analisadas, propõe-se um paralelo entre a CDPA e o entendimento de experiência contido no ensaio $O$ Narrador, de Walter Benjamin, para quem a experiência torna-se conhecimento pelo acúmulo, prolongamento e desdobramento dessa experiência. Apresenta-se o entendimento de que, apesar de se constituir na Cia. Oficial de Dança do estado de Minas Gerais, a CDPA não se vê isenta de enfrentar desafios, mantendo-se em cena com dinâmicas de uma dança de resistência continuada e em interação com o contexto comumente presente na dança teatral contemporânea.

Aplica-se aqui o entendimento de dança teatral, característico da organização de companhias estatais, a partir de Fazenda (2012), que a conceitua como sendo um gênero de execução realizada por agentes selecionados - Bailarinos, ou performers, Coreógrafos - e demais colaboradores com propósitos e pressupostos técnicos e estéticos determinados, a serem presenciados por um grupo de espectadores em um lugar específico, separado de outros eventos sociais. Ressalta-se que a dança teatral contemporânea alcança espaços diversos, como galerias de arte, salas, jardins, espaços públicos, fachadas de prédios, etc., transformando, consequentemente, não só a relação espacial entre artista e público, mas interferindo e ressignificando as formas de relacionamento entre eles (SILVA, 2005).

Destarte, convoca-se um olhar de apreciação do sentido de experiência em Benjamin entrelaçado à compartilhada pela CDPA, não um olhar ingênuo, mas voltado à simplicidade intrínseca a processos sintéticos.

\section{Tecendo redes de experiência entre Benjamin e a CDPA}

Walter Benjamin (1892-1940) foi um importante filósofo alemão do século $X X$, que se dedicou a reformular a crítica do entendimento de experiência ao longo de sua vida literária, contextualizando-a historicamente no transcorrer das transformações estruturais pelas quais a humanidade passou. Em consonância com Benjamin e entendendo-se o apelo que a questão da experiência tem para boa parte dos artistas, esta é considerada por este texto como uma forma legítima e válida de conhecimento (OLIVEIRA, 2009).

Entende-se que os sentidos de experiências contidos nos ensaios de Benjamin vão se transformando ao longo de sua vida literária, colaborando uns com os outros, não chegando a contradizerem-se (entre si) em sua totalidade. $O$ entendimento de experiência [erfahrung], presente em quatro dos ensaios de Benjamin (Experiência, 1913; Sobre o programa da filosofia do porvir, 1918; Experiência e pobreza, 1933; O Narrador, 1936), e de vivência [erlebnis] presente em um deles (So- 
bre alguns temas baudelairianos, 1940) varia de sentido e expõe a inquietação de Benjamin a respeito desse tema.

Mas o que se entende pelo sentido benjaminiano de erfahrung e erlebnis? Em que este ou aquele se aproxima de uma discussão atualizada da questão da experiência estética na arte da dança da CDPA? Tem-se como experiência [erfahrung] um conjunto de ações e ritos passados tradicionalmente de geração em geração e conservados pela memória, abrigando atos, gestos, sentimentos e expressões comunitários. Estes se consubstanciam por ações comportamentais de expressão individual que, juntos, formam uma rede coletiva de significados aceitos e partilhados como valores, saberes e conhecimento dessas comunidades. Como vivência [erlebnis], entende-se a experiência advinda da vivência pessoal, característica daquele indivíduo presente no ato do acontecimento. A vivência abrange a singularidade do ato efêmero, apegando-se exclusivamente à sua vida prática, sem maiores vínculos com o passado, e pela curta duração, não se registrando em sua memória mais profunda. Nesta se encontram as excitações sensoriais - visão, audição, tato, paladar, olfato -, exercendo efeito constante e imediato nas questões relacionadas à sobrevivência do indivíduo.

Apesar de Benjamin entender que a capacidade de compartilhar experiência esteja em baixa na modernidade, este texto infere ser a CDPA uma ilha de resistência desse compartilhamento na contemporaneidade. Considerando-se os processos do dia a dia do fazer artístico da CDPA, o entendimento de erfahrung se mantém dinâmico e atualizado, propício aos processos de compartilhamento das suas experiências e do conhecimento delas proveniente. O artista de dança da Companhia é a síntese do início, meio e fim da experiência no seu próprio corpo em um processo de aprendizado e profissionalização, estabelecendo uma práxis coletiva de observar, copiar, aprender, repetir, dançar, interpretar, observar, e assim por diante, em ações continuadas de adaptação e transformação. Nesse processo, narrador e ouvinte/mestre e Bailarino intercambiam valores artístico-culturais transmitidos por gerações, articulando habilidade corpórea e linguagem investida de sentido.

Ressalta-se que tal processo mantém um ritmo artesanal, lento, distinto do ritmo acelerado dos eventos contemporâneos em que se é literalmente bombardeado por um excesso de estímulos diversos, tendo-se acesso em tempo real às diferentes informações e mídias. Contudo, tal formato não se encaixa no modo de operar da CDPA. Como boa parte de outras tantas profissões, a exercida pela CDPA necessita de uma dedicação intensa (e continuada). Para além do intelecto e do espírito, o que se molda é o corpo do artista, exigindo-se tempo, o qual varia de pessoa para pessoa. E, em se tratando de habilidades corporais, o que se aprende rápido se esquece rápido. O tempo compartilhado nos processos artísticos da Companhia pode ser comparado à recíproca relação entre as figuras medievais benjaminianas do mestre sedentário e o artífice viajante, trabalhando juntos na mesma oficina (BENJAMIN, 2012).

Embora erfahrung seja ação central na práxis da CDPA, o entendimento erlebnis também está contido em seu processo, levando-se em consideração a transformação do entendimento de experiência contida no ensaio Sobre alguns temas baudelairianos, de Benjamin. Cada Bailarino que integra a CDPA, influenciado por diversos estímulos da contemporaneidade, está sujeito aos impactos dos mes- 
mos e ao que Benjamin chama de experiência pobre, constituída de fatos isolados, influenciada pelo prazer dos sentidos. Essa nova forma de experiência moderna faz parte dos integrantes da Companhia, configurando-se por ações individuais articuladas por vivências. Afinal, não é a experiência substância da tradição, tanto na vida privada quanto na coletiva? (BENJAMIN, 2012).

Ressalta-se, a esta altura, o jogo relacional entre experiência e vivência e a reciprocidade entre "memória" e "esquecimento". A memória se constitui de aquisição, formação, conservação e invocação de informações, também chamada de aprendizagem, no entendimento de só ser possível gravar aquilo que foi anteriormente aprendido (IZQUIERDO, 2002). Os processos de funcionamento do cérebro pesquisados pela Neurociência já esclarecem episódios importantes, por exemplo, ser o cérebro seletivo. Isto significa que lembramos o que foi aprendido, tanto quanto podemos dizer que somos aquilo que resolvemos esquecer. $O$ esquecimento faz parte dos mecanismos funcionais de defesa e estratégias do cérebro humano, preservando o que é significativo e eliminando o que é irrelevante. Nesse sentido, as memórias se constituem referências afetivas e sociais e têm relação direta com a recordação dos costumes e das tradições de suas respectivas comunidades, conferindo-lhes identidade. Assim sendo, retoma-se o entendimento da equivalência entre experiência e conhecimento conectado ao de narrativa e memória presentes no ensaio literário de "O Narrador - considerações sobre a obra de Nicolai Leskov".

Ao investigar a obra de Leskov, Benjamin constata as diferentes condições entre as origens da narrativa tradicional (outrora sinônimo de autoridade e sabedoria) e da moderna, apreendendo que a arte de narrar está em vias de extinção, sendo raras as pessoas que sabem narrar devidamente (BENJAMIN, 2012). O filósofo percebe que o declínio desse compartilhamento de experiências afasta o homem de sua cultura, de seus valores éticos e morais. Em oposição, a modernidade produz um estado de tempo/espaço em que o interesse volta-se para o imediatismo, para o que é mais fácil e rápido de se alcançar. Benjamin teme pelos efeitos subjetivos dos fatores socioculturais das forças transformadoras do capitalismo e das mazelas decorrentes destas ${ }^{1}$. Ou seja, Benjamin alerta seu leitor quanto ao perigo da extinção do hábito da narrativa e da consequente extinção da experiência coletiva comunicável que dá sentido integral à existência humana, interferindo no conhecimento, na apreensão (e representação) da história - a história que não é narrada não é lembrada, não se transforma em memória, nem preserva o saber contido na tradição.

Em O Narrador, Benjamin faz uso de duas figuras ilustrativas ordinárias do narrador ou contador de história para discutir as condições possíveis da experiência moderna que, por sua vez, vão colaborar na transposição do entendimento de experiência para a arte da dança: o camponês sedentário, conhecedor das tradições dos antepassados e que se encontra fixado em um lugar; e o marinheiro comerciante, que se encontra em trânsito, trazendo (e levando) histórias de terras

\footnotetext{
${ }_{1}^{1}$ Entre estas, citam-se: a experiência moderna ardilosa e falsa; a pobre realidade existente nas fábricas têxtis no sistema capitalista com produção massificadora; os novos meios literários diferentes da narrativa, o romance e a informação, o primeiro não mais vinculado à tradição oral e ao compartilhamento interpessoal presentificado no ato da narrativa, mas isolado em uma leitura solitária, o segundo não se atrela a transmitir um conhecimento senão o de notícias isoladas dadas de forma objetiva, rasa, vindo logo a cair no esquecimento, não se efetivando em conhecimento; e, o auge, a Primeira Guerra Mundial, com seus traumas, miséria, abalos éticos, inflação e aniquilação do espírito humano (BENJAMIN, 2012).
} 
distantes (BENJAMIN, 2012, p.215). Com o consequente desaparecimento do contador de histórias desaparece também o seu aconselhamento sábio de experiência de vida e demais experiências a ele compartilhadas.

Resistindo à falência moderna na capacidade social de comunicação apontada por Benjamin, têm-se os procedimentos estéticos, técnicos e reflexivos da CDPA, propondo-se a equivalência entre as figuras do narrador e do artista de dança, que compartilham suas experiências reciprocamente - o narrador/mestre e o ouvinte/bailarino. Destacam-se, portanto, três aspectos fundamentais da partilha de experiência segundo Benjamin (2012): em primeiro, a experiência é compartilhada entre pessoas de um mesmo grupo e de interesses comuns, em que o que fala compartilha sua experiência com aquele que quer ouvi-la; em segundo, tal processo caracteriza-se pela natureza artesanal, compartilhado de forma lenta e presencial, o que favorece a sedimentação progressiva de conhecimento, tirando dela proveito; e, em terceiro, vê-se a sabedoria contida na narrativa envolvendo um saber prático, que pode vir na forma de uma advertência ou de um aconselhamento.

Correlacionando-se os aspectos fundamentais com a CDPA em sua construção da artesania do corpo, tem-se o moldar gradual do conhecimento da arte da Dança no corpo do artista (como as mãos do oleiro na argila do vaso); o compartiIhar o conhecimento (técnico, artístico e reflexivo) por artistas locais (camponeses sedentário), nacionais ou internacionais (marinheiros comerciante), de forma presencial, corpo a corpo; mestre e aprendiz compartilham de um mesmo espaço de trabalho, em um ambiente onde todos têm interesses e valores comuns de ouvir e receber aconselhamentos. $\mathrm{E}$, de uma forma bastante interessante, como esclarece Benjamin ao seu leitor, tal processo de assimilação de conhecimento efetiva-se em uma rede de camadas profundas que se fixam na memória, por um estado eficiente de distensão psíquica (BENJAMIN, 2012, p. 221). Ou seja, estado que dispensa análise psicológica, no qual o conhecimento é compartilhado de uma forma natural pelo processo da repetição diária no fazer artístico do Bailarino, similar ao ato de contar e recontar histórias pelo narrador benjaminiano, até que o artista assimile naturalmente a essência da linguagem da dança - o movimento expressivo intencionalmente coordenado.

$\mathrm{Na}$ intenção de preservar os processos artísticos pela sua tradição prática construindo sua própria história, a CDPA pode ser entendida como um lócus em que se processa uma força de resistência nos procedimentos de prática e reflexão de dança. "Resistência" entendida pelo sentido etimológico da palavra de "resistir a", no ato de conservar-se firme a uma ação contrária. "Resistência" também entendida por Benjamin, que, apesar de não tratar explicitamente desse conceito em seus ensaios, a discute em suas análises sobre as transformações pelas quais passa a modernidade ${ }^{2}$. Percebe-se a resistência da CDPA quando esta se mantém na contramão da relação imediatista da modernidade, ao manter e buscar conservar as relações interpessoais de seu grupo social, tanto quanto no intercambiar de seus saberes artísticos. Entende-se "resistência" na dança pela CDPA objetivamente pelo seu prefixo "re", que indica um estado de insistência, de permanência, de existir e se manter de pé por mais de quatro décadas de trajetória artística. Em se tratando

\footnotetext{
1 Acrescentam-se as novas tecnologias que corroboram na complexidade das relações sociais, em parte massificadas, e, por outra, isoladas em um mundo individualizado, corroborando para o fim da experiência, a ausência da memória e o desconhecimento do sentido essencial da história (BENJAMIN, 2012).
} 
da arte da Dança, não se está falando de qualquer coisa, e sim de uma respeitável existência. Resistência é insistir em estar presente!

Mantendo-se o raciocínio proposto, trata-se a seguir de três movimentos expressivos da CDPA nos quais se destacam ideias, experiências e obras artísticas que colaboram para o entendimento de permanência (e resistência) em dança da Companhia no cenário artístico da dança teatral de Minas Gerais.

\section{Movimento I}

A CDPA foi criada em Belo Horizonte em 1971, ano seguinte da inauguração da, então, Fundação Palácio das Artes, nomeada Fundação Clóvis Salgado a partir de 1978, instituição jurídica que administra o principal centro cultural do Estado de Minas Gerais. A Companhia compõe-se pela união do já estabelecido "Balé de Minas Gerais" e da "Escola de Dança", ambos dirigidos pelo Bailarino gaúcho e Mestre de Dança Carlos Leite, primeiro Artista Professor responsável por abrir literalmente os horizontes da capital mineira para a dança teatral profissional. A CDPA se estabelece como primeiro Corpo Estável a ser oficialmente constituido junto à Fundação, antecedendo à Orquestra Sinfônica de Minas Gerais - OSMG, em1976, e ao Coral Lírico de Minas Gerais - CLMG, em 1979. Ressalta-se que esses são tempos em que o país se encontra sob o regime da ditadura militar, época caracterizada por repressão e censura. Carlos Leite torna-se, então, a personalidade artístico-cultural capaz de sustentar os ideais progressistas instigados anos antes por Juscelino Kubistchek, quando prefeito de Belo Horizonte (período referente ao início das obras da Fundação, no ano de 1944). Radicado em Belo Horizonte desde o ano de 1948 e já desenvolvendo suas atividades de formação profissional em dança, o Professor Carlos Leite, como costuma ser chamado carinhosamente por seus alunos, mostra-se como o artista capaz de, a partir de sua experiência profissional nacional e internacional (como o marinheiro comerciante), compartilhar com e entre os mineiros os conhecimentos aos moldes da Companhia Oficial do centro artísticocultural mais importante do país, a Companhia Oficial do Teatro Municipal do Rio de Janeiro, do qual foi integrante e Primeiro Bailarino por mais de uma década.

Mas, para que Leite chegue a ser o representante oficial da dança profissional local, será necessário o acontecimento de muitas danças (movimentos) preliminares de resistência, antes mesmo da inauguração da (então) Fundação Palácio das Artes, instituição que abrigará a futura Companhia Oficial de Dança do Estado. O pioneirismo de Leite, fator singular de sua vida artística, significará, por vezes, ações de uma dança de resistência. Cita-se a ação estrategista promovida pelo Professor por ocasião da demora na finalização da obra da Fundação Palácio das Artes, obra por vezes interrompida (e reiniciada) durante anos. Leite mobiliza sua Companhia "Balé Minas Gerais" buscando a atenção da sociedade e a sensibilização do poder público. Destaca-se, nesse sentido, a reportagem da Revista "Silhueta" (s.n.) do ano de 1954, que se constitui em um fragmento precioso da história, que ilustra algumas das dificuldades, a determinação e a perseverança enfrentadas pelos pioneiros da dança profissional de Belo Horizonte. O artigo intitulado "Artes à Sobra de Ruínas", literalmente, apresenta cenas de resistência, verdadeiro paradigma de perfil performático em Belo Horizonte em meados do século passado. 
As imagens da revista revelam uma situação inusitada, fora do comum e digna de estranhamento por parte dos transeuntes da Av. Afonso Pena, local da obra de construção da Fundação. De uma forma poética e conceitual, os artistas da dança, mais que marcarem presença, marcam território, lutando por seus objetivos e posicionando-se politicamente. As imagens dos artistas, suas formas leves e figurinos delicados contrastam com as formas do chão de cimento áspero, ferros retorcidos, tapumes de madeira empoeirados sob o sol a céu aberto (Figura 1).

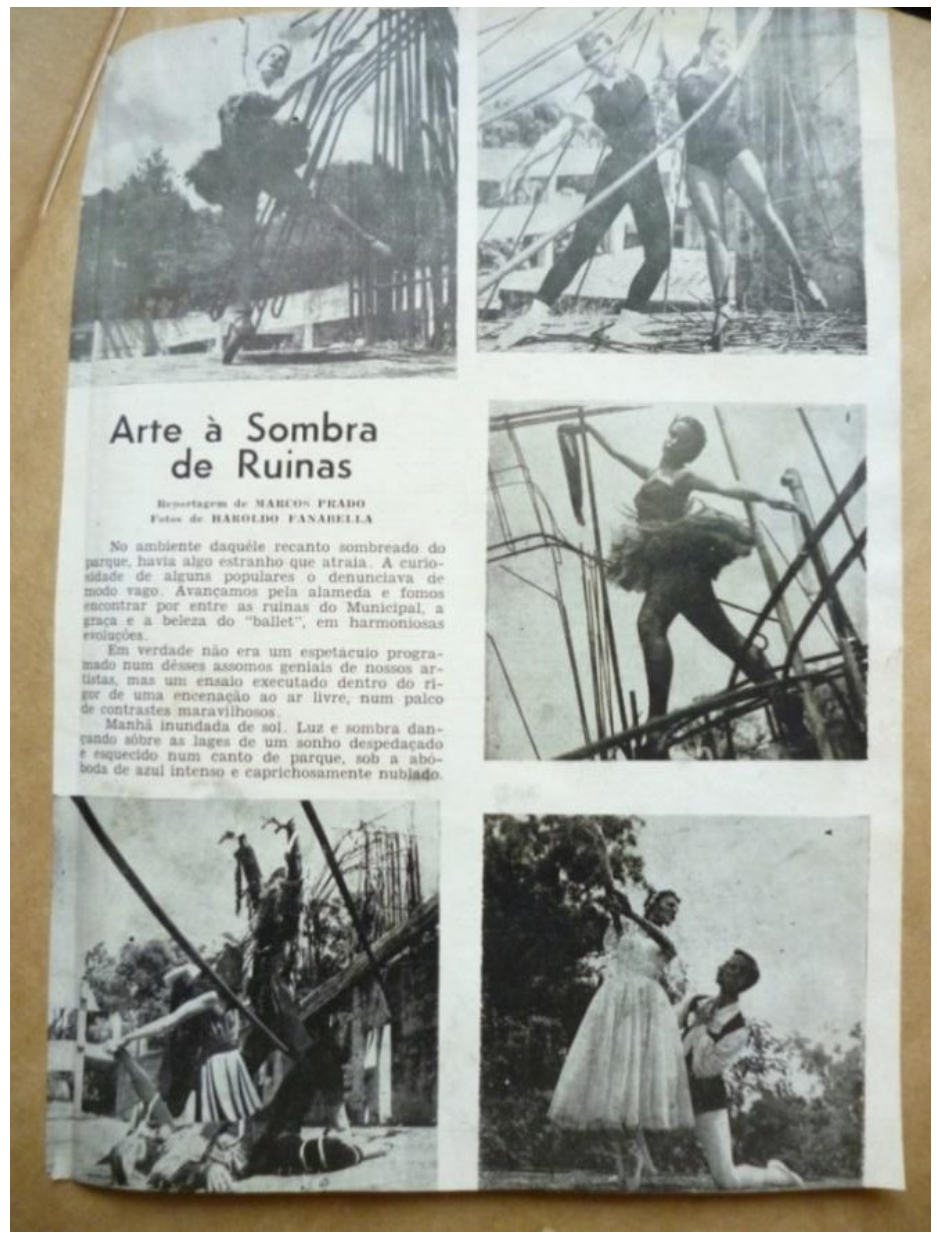

Figura 1: "Arte à Sombra de Ruínas". Revista SiIhueta (s/n). Reportagem de Marcos Prado.

Belo Horizonte, 1954.

Fotografia de Haroldo

Fanabella. Acervo: Dulce Beltrão.

Quinze anos depois, Leite realizará sua missão, a saber, constituir um Corpo de Baile oficial na cidade de Belo Horizonte, processo similar ao apontado por Benjamin, no que diz respeito ao acúmulo de experiências em uma lenta superposição de camadas transformadas em conhecimento.

A Companhia segue construindo sua trajetória artística eclética, trabalhando com diretores e coreógrafos convidados, vindo a ter uma experiência de natureza contemporânea ao propiciar uma ponte entre tradição e modernidade em uma preliminar experiência em seus procedimentos estéticos e operacionais. A obra Tribana do ano de 1983, com Direção Geral de Dulce Beltrão, introduz a Companhia em um novo formato de estética artística. A Diretora e dois Bailarinos integrantes da CDPA, David Mundim e Lucas Cardoso, coreografam em parceria mútua. A proposta inédita de Beltrão revela-se arrojada para os padrões da Companhia até então, colocando os Bailarinos em contato direto com o público, desde o foyer do grande teatro do Palácio das Artes, adentrando pela plateia, chegando à ação plástica (acrobática) 
de Bailarinos descerem pelo parapeito do balcão e interagirem com o público, rumo à caixa preta do palco. Tal experiência surge em meio aos desejos da CDPA de buscar uma nova estética contemporânea de dança, em um contexto no qual o Brasil respira seus últimos anos de uma Ditadura Militar enfraquecida (1964-1985), voltando-se para a abertura política e se preparando para um governo democrático (SCHWARCZ; STARLING, 2015).

\section{Movimento II}

Em um segundo movimento, com cerca de 20 anos de existência, a Companhia segue passando por outros diretores artísticos, encontrando um período estético estável em sua trajetória, com a profícua Direção Artística de seu primeiro Coreógrafo "prata da casa", o Maître Tíndaro Silvano, que por cerca de cinco anos consecutivos atua como Coreógrafo Residente da CDPA (ALVARENGA In: MENCARELLI et al., 2006). Silvano passa a integrar a CDPA, saindo diretamente da Escola Profissionalizante de Leite (situada no Palácio das Artes) para a Companhia, antes de seguir vivenciando novas experiências profissionais em outras companhias nacionais e internacionais, entre elas: Teatro Guaíra (Curitiba); John O'Brien (Londres); Raymond Franchetti (Paris); e, de volta ao Brasil, Theatro Municipal do Rio de Janeiro (RJ). A ação de ir e vir de Professores, Coreógrafos e Bailarinos constitui-se um fluxo característico contido na tradição da arte da dança teatral, similar às figuras de narrativa benjaminianas. Como Coreógrafo Residente da CDPA, Silvano conta com uma equipe bem ajustada, a saber, Patrícia Avellar, Bailarina, Gerente de Produção, Diretora, e Lydia Del Pecchia, Bailarina, Assistente de Direção e Ensaiadora. Tal equipe favorece o entendimento de como a arte da Dança constitui-se em um trabalho artesanal, processo de natureza lenta, no qual se sublinha ser o Artista Cênico a matéria-prima, no qual e pelo qual as camadas de experiência se fazem sedimentar.

Destaca-se a obra Relâche (1995) de Tíndaro Silvano, em homenagem aos 100 anos da Arte do Cinema. Similar às narrativas que são contadas e recontadas, esta se inspira no balé homônimo realizado pelo Balé Sueco de Rolf de Maré, em Paris, no ano de 1924, considerada obra marco dos artistas vanguardistas do Movimento Dadaísta encabeçado pelo pintor francês Francis Picabia, e o Bailarino e Coreógrafo sueco Jean Borlin (Figura 2).

Figura 2: Capa frontal do Programa da obra Relâche - CDPA. Belo Horizonte, 1995. Acervo: Centro de Convivência, Informação e Memória João Etienne Filho/FCS.

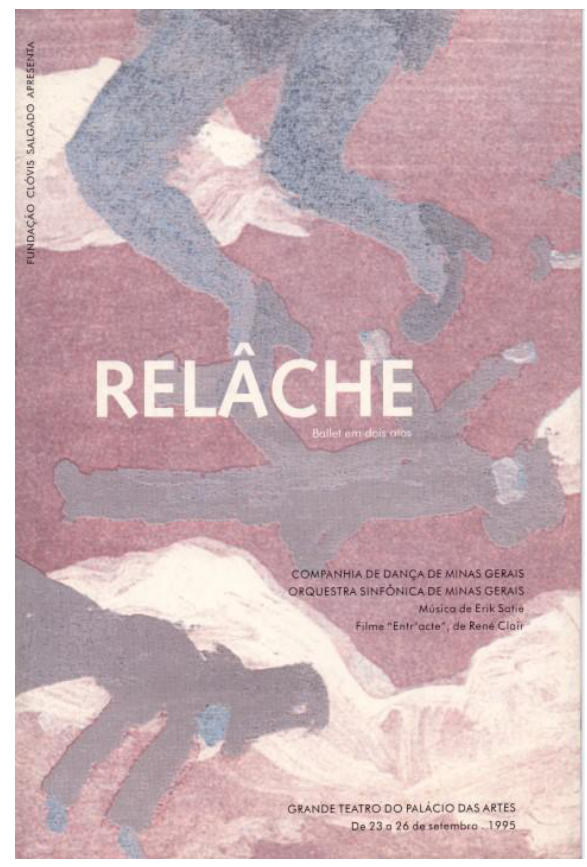


Relâche pode ser considerada uma dança de resistência, por conter uma dose a mais de ousadia e crítica ao consumismo, característicos do Movimento Dadaísta, que tomou corpo durante o período entreguerras. Obras como Relâche deixaram um irreversível movimento de experimentação plástica, introduzindo elementos de características performáticas, de leitura não linear, dando sentido ao acaso ou aos efeitos acidentais na arte da metade do século $\mathrm{XX}$, abrindo campo para a arte conceitual na cena da dança teatral desde então, e alcançando a CDPA no Terceiro Milênio em uma releitura que pode ser considerada, no mínimo, bem elaborada, ao promover um diálogo de integração entre outras esferas das artes Cinema, Artes Plásticas, Música e História da Arte.

Entre os desafios da Companhia nesse período, consta sua projeção nacional, mantendo-se afinada às demandas da dança teatral do Brasil. A dança de resistência se faz presente nas diversas reuniões de negociação e mediação entre Direção Artística da CDPA e Instituição Fundação Clóvis Salgado. Ou seja, tem-se uma constante negociação com as instâncias superiores da Instituição pela conscientização do que se compõem as especificidades e as demandas operacionais de uma Cia. Oficial de Dança em seus projetos de manutenção e criação artísticas. Como sustentar financeiramente as viagens ao aceitar os diversos convites feitos à CDPA para "abrir" os tradicionais Festivais de Dança, tais como os de Joinville, Bento Gonçalves, Festival Nacional de Dança do Recife, entre outros? Como sustentar financeiramente a viagem de todos os integrantes da Companhia? Como resolver, entre estes, os que serão escolhidos para o elenco, ou não, já que a participação de todos não se faz possível? Todavia, nesse segundo movimento, vêse uma Companhia em seu período mais estável de criação e produção artísticas, inserindo-se no circuito nacional da dança teatral. A busca da CDPA por um perfil artístico que a identifique esteticamente amadurece rumo a atender suas aspirações expressivas de visão de mundo, na relação indivíduo/sociedade, artista/público.

Mas a cada época corresponde uma forma de percepção, uma inquietação e uma reação, que acabam por se configurar em forma de arte. Recentes inquietações internas já se fazem presentes na CDPA e buscam-se por novos formatos na relação Direção Artística/Bailarino, distintos da hierarquia tradicional, mas voltados para uma coparticipação nos projetos de criação artística. A Cia se encontra em seu terceiro Movimento, caracterizado por um processo de experimentação constante, que pode ser denominado reflexão-pesquisa, dando início ao formato de coautoria na criação coreográfica compartilhada.

\section{Movimento III}

Incentivada pela Direção Artística da Bailarina e ex-integrante da Cia Cristina Machado e no final da sua terceira década de existência, a CDPA inicia um perfil estético sintonizado com os movimentos artísticos de sua época, participando de Festivais, Fóruns e Mostras de âmbito nacional e internacional, como em Israel, na Espanha e na França. A Cia explora as novas experiências relacionadas ao perfil de Bailarino Pesquisador, adotando inicialmente o método conhecido como BailarinoPesquisador-Intérprete - BPI, desenvolvido pela Bailarina mineira, a Pesquisadora Graziela Rodrigues. Este (perfil) abriga, a partir do terceiro milênio, um processo 
provocador de desdobramentos artísticos de natureza prática, teórica e de consciência emocional, processo subjacente à produção estética da Companhia até os dias atuais. Mais que uma técnica, o método BPI envolve um processo maior de amadurecimento integral, físico e emocional. do sujeito bailarino (RODRIGUES, 2005).

Após passar por um significativo período de laboratório de pesquisa com a Companhia valorizando o envolvimento físico e emocional do Bailarino, processo dirigido por Rodrigues e vivenciado no campo fora, e dentro, da cidade de Belo Horizonte, destaca-se a primeira obra que introduz o processo de coautoria na CDPA, Entre o Céu e as Serras, no ano de 2000, com Direção Geral de Cristina Machado, Coreografia de Luiz Mendonça (Figura 3).

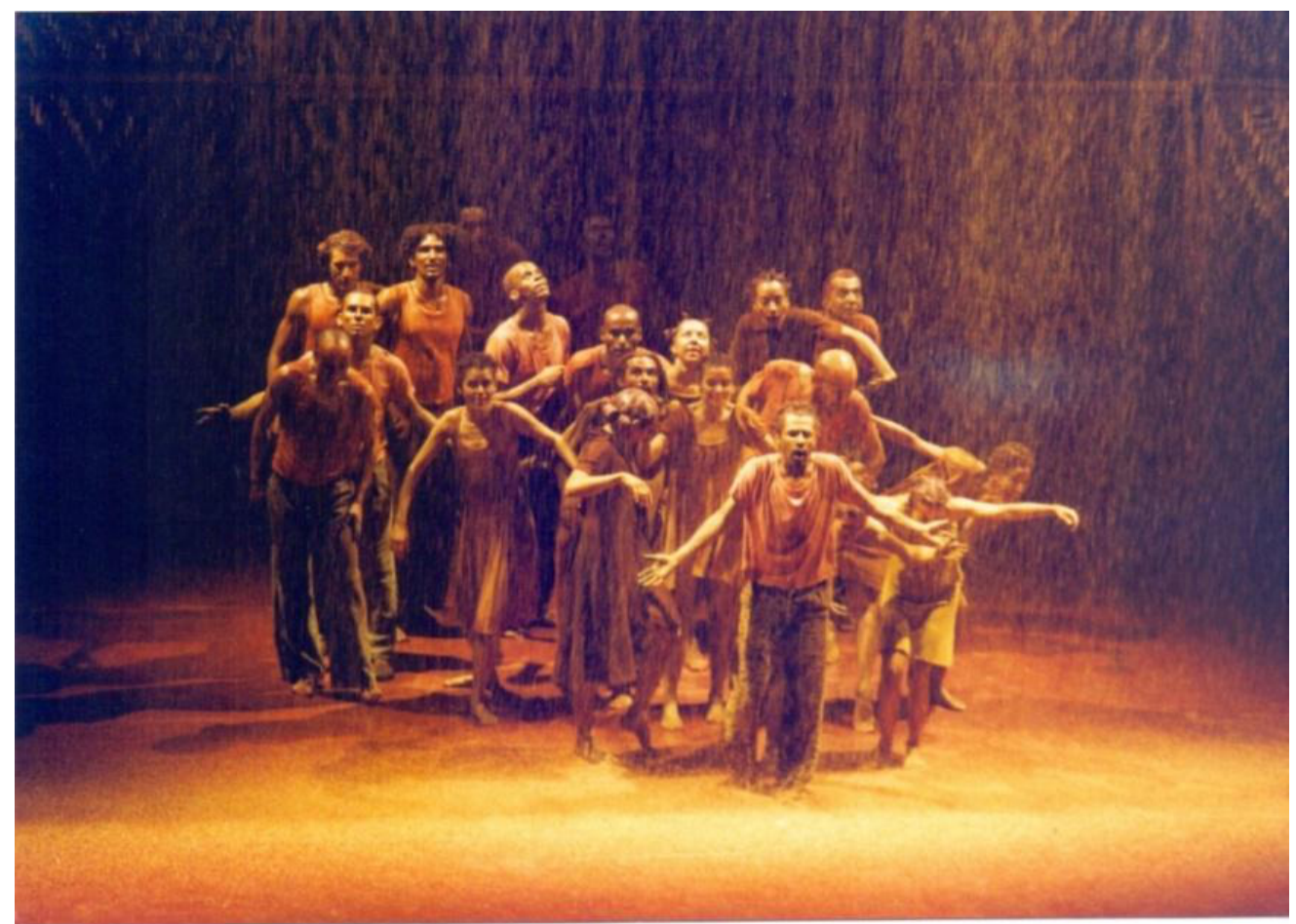

Figura 3: Obra Entre o Céu e as Serras - CDPA. Fotografia de Sérgio Roberto (s/d). Acervo: CDPA/FCS.

Os desafios da CDPA continuam relacionados à busca pela aproximação entre arte e vida, e, por isso mesmo, por vezes não produz obras palatáveis e de fácil digestão aos olhos do público. Sônia Mota, Diretora Artística que sucede a Direção de Cristina Machado, também compartilha suas experiências artísticas com a CDPA, não deixando que se perca a consciência e sensibilidade artística em relação ao material humano que a Diretora tem em mãos, imprimindo sobre este barro, feito de carne e espírito, sua marca, como as mãos do oleiro (BENJAMIN, 2012). Literalmente, por sua vez, Mota exercita sua dança de resistência ao lidar com as instânci- 
as superiores da FCS durante o período de sua Direção Artística (2010-2013), descobrindo ser a burocracia da Instituição infinitamente lenta e complexa. No entanto, a Diretora, ao compartilhar suas vivências com a Companhia, corrobora com o entendimento benjaminiano de experiência, na ação de realizar seu ofício de natureza artesanal. Em seus processos criativos, a Artista trabalha com a memória coletiva construída a partir de lembranças individuais dos Bailarinos, dando contorno ao tempo, à memória e às experiências provenientes destes (Mota, Programa da obra 22 Segredos, 2009).

Mota trata com habilidade e sensibilidade a Companhia, relação própria de quem sabe com quem e com o que se está lidando, ou seja, as questões que envolvem uma companhia que percorreu 40 anos de trajetória artística e, com ela, também sentiu o tempo passar, não em um sentido nostálgico, mas com celebrações de quem muito viveu e vive a Arte da Dança.

\section{Continuidades}

Discutiu-se neste artigo o entendimento de que a CDPA desenvolve um potencial de expressão artística em seus movimentos de uma dança continuada, revelando uma sabedoria com o passar do tempo advinda, em boa parte, de procedimentos de acúmulo, prolongamento e desdobramentos de suas experiências, ultrapassando mais de quatro décadas de existência. Movimento gerador de experiências que se transformam em conhecimento. Estado de arte que tem possibilitando a seus artistas a coragem de se expor física e emocionalmente ao tratar de assuntos que abalam ou incomodam a sociedade contemporânea. O caminho de inspiração trilhado pela Companhia tem se pautado em projetos de criação coletiva no processo de formação de um Bailarino Pesquisador, e por isso autor da sua própria dança, em uma trama com a dança do seu grupo. Compreende-se, assim, a capacidade de entrelaçamento da CDPA com as reflexões de Benjamin em seu entendimento de experiência, essencialmente desenvolvidas em seu ensaio $O$ Narrador.

Quebrando paradigmas, o perfil artístico da CDPA constitui-se de uma companhia de vanguarda para o Estado tanto quanto para o padrão comumente adotado pelas demais Companhias Oficiais de dança do país. A Cia distingue-se não só por sua opção estética contemporânea como também pela relação de criação artística compartilhada (tradicionalmente hierárquica em Cia. Oficiais), causando, por vezes, estranhamento de muitos e admiração de poucos, até que esse perfil venha a se tornar familiar pela reorganização da percepção social, vindo a se transformar em códigos reconhecíveis, como ocorre no interior de grandes períodos históricos (LE GOFF, 2003).

Concluindo, pode-se dizer que, embora a CDPA tenha alcançado uma identidade que se diferencia das demais Companhias Oficiais do país, pressupondo uma liberdade artística na criação compartilhada em seus trabalhos coreográficos, a mesma se vê em um constante desafio de permanência e renovação. Isto se faz pela construção de uma trajetória artística pautada no entrelaçamento entre vida e arte no fluxo de experiências transformadas em significado. Esta (experiência), além de tocar a própria CDPA, alcança o público e o atravessa (LARROSA, 2002), consubstanciando sua trajetória artística em movimentos de literalmente abrir espaços no 
mover, no sentir, no pensar sobre o significado da expressão humana por meio da Arte da Dança.

\section{Referências}

ALVARENGA, Arnaldo Leite de. A Companhia de Dança Palácio das Artes - Os Primeiros Tempos: Carlos Leite e o Ballet de Minas Gerais (1948-1971). In: ; MENCARELLI, Fernando Antonio; MALETTA, Ernani de Castro; ANDRADE, Maurilio. Corpos Artísticos do Palácio das Artes: Trajetória e Movimentos. Belo Horizonte, 2006. p. 58-115.

BENJAMIN, Walter. O Narrador. In: Magia e Técnica, Arte e Política: Ensaios sobre Literatura e História da Cultura. Obras Escolhidas I. São Paulo: Brasiliense, 2012. p. 213-240.

FAZENDA, Maria José. Dança Teatral: Ideias, Experiências, Ações. 2. ed. Lisboa: Colibri; Instituto Politécnico de Lisboa, 2012.

IZQUIERDO, Iván. Memória. Porto Alegre: Armed, 2002.

LARROSA, Jorge. Notas sobre a experiência e o saber da experiência. I Seminário Internacional de Educação. Revista Brasileira de Educação, Rio de Janeiro, n. 19, p. 20-28, jan./fev./mar./abr. 2002.

LE GOFF, Jacques. História e memória. Tradução Bernardo Leitão. 5. ed. Campinas, SP: Ed. da Unicamp, 2003.

OLIVEIRA, Luiz Sérgio de. (Org.) Walter Benjamin: arte e experiência. Rio de Janeiro: Nau; Niterói, RJ: EdUFF, 2009.

RODRIGUES, Graziela Estela. Bailarino-pesquisador-intérprete: processo de formação. 2. ed. Rio de Janeiro: Funarte, 2005.

SCHWARCZ, Lilia Moritz; STARLING, Heloisa Murgel. Brasil: uma biografia. São Paulo: Companhia das Letras, 2015.

SILVA, Eliana Rodrigues. Dança e pós-modernidade. Bahia: EDUFBA, 2005.

Recebido em 03/02/2018 - Aprovado em 13/09/2018.

Como citar:

MEIRELES, T. M. S. Cia. de Dança Palácio das Artes: movimentos de uma dança de resistência. ouvirOUver; Uberlândia, v.14.n.2, p 522-534, jul./dez. 2018. Disponível em: http://www.seer.ufu.br/index.php/ouvirouver;

DOI:http://doi.org/10.14393/OUV23-v14n2a2018-19

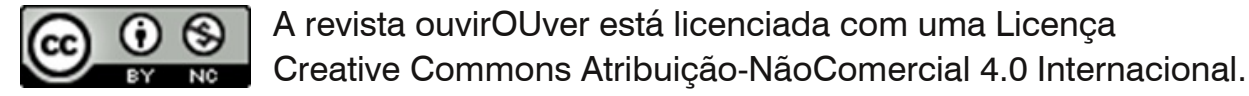

ouvirouver Uberlândia v. 14 n. 2 p. 522-534 jul.|dez. 2018 